\title{
Application of Terrestrial Close-Range Photogrammetry for Estimating Stem Volume of Tree Species in Subtropical Forest in Okinawa, Japan
}

\author{
Yuki Tamaki ${ }^{1}$, Masashi Konoshima ${ }^{2 *}$
}

\begin{abstract}
A nondestructive, practical and efficient in-situ tree measurement approach is desperately needed to address the problem of large data volume, enhancing data quality and improving our understanding of stem volume estimation in Okinawa. This issue has become important because of two forestry related policy issues that have received lots of attention in Okinawa. The two issues are the introduction of carbon certification program and the nomination of northern Okinawa Island as a World Natural Heritage site. In this study, our attention was turned to a more recent emerging low cost approach for estimating stem volume with minimum environmental impact on the site, that is, the terrestrial closerange photogrammetry. We explored the usefulness and evaluated the limitations of the approach. For examination of the accuracy of terrestrial photogrammetry, we compared the stem volume estimated from photogrammetry with the stem volume computed based on direct measurement using 3D magnetic motion tracker. The error of the estimated volume was $0.0053 \mathrm{~m}^{3}$ root mean square error (RMSE) and the estimated surface was $0.0714 \mathrm{~m}^{2}$. In order to explore the efficiency of the photogrammetry, we extended our approach to include the simultaneous reconstruction of $3 \mathrm{D}$ images of multiple tree stems within a plot. Using one of the latest image-processing software, we successfully reconstructed $3 \mathrm{D}$ models of 11 stems within a plot and computed stem volume for each. The error of the estimated volume and surface were $0.0128 \mathrm{~m}^{3}$ and $0.1940 \mathrm{~m}^{2}$, respectively.
\end{abstract}

Keywords: terrestrial photogrammetry, stem volume, subtropical forest

\section{Introduction}

In response to the threat posed by global climate change to our society, policy makers and local governments in Japan have adopted the use of forest certification as a tool to encourage forest carbon sequestration and mitigate the impact of greenhouse gas (GHG) induced climate change. The office of Okinawa prefecture in Japan has joined this effort and has introduced a certification program in April of 2017 (Okinawa Prefecture 2017). According to the office in Okinawa, just like many other prefectures in Japan, the estimation of carbon sequestration is based on IPCC Guidelines for National GHG Inventories (Eggleston et al. 2006). Here, both above - and below - ground carbon stocks are estimated from tree stem volume and other predefined parameters (such as wood density, biomass expansion factor, root-shoot ratio). Against this background, it is important that an accurate and detailed measurement of individual tree stem is carried out to ensure a reliable estimate of carbon stocks and the monitoring of global carbon stock changes (IPCC 2014).

Despite the importance and relevance of this subject matter, there is lack of data and information, as well as appropriate methods for measuring stem volume and biomass of trees in subtropical forest (Takashima 2011; Wu et al. 2015; Xu et al. 2015; Xiang et al. 2016). This therefore, limits the ability to properly evaluate forest carbon sequestration in subtropical forests. Also, unlike major coniferous tree species found on the main islands of Japan, simple cylinder models are inappropriate and unable to capture or represent the complex stem structure that feature in many subtropical tree species in Okinawa. This adds another layer of complexity to the difficult and challenging task of estimating stem volume in these regions (Drake et al. 2002; Arief 2009; Omar et al. 2014). Furthermore, conducting in-situ destructive sampling (i.e. cutting down trees for direct measurements) which is a necessary process to ensure accurate measurement for tree volume and biomass, has become extremely controversial and difficult because of the government's decision to nominate the northern part of Okinawa Island (Okinawa Godo Law Office 2018) as a World Natural Heritage site. Cutting down trees in and around a designated World Heritage site may draw a lot of environmental protest. It must also be pointed out that the commonly available volume estimation tools such as volume

Received Feb. 13, 2019; Accepted Mar. 18, 2019

1 Forests Management Division, Okinawa Prefectural Government, Japan

2 University of the Ryukyus, Japan

*Corresponding Author: konoshim@agr.u-ryukyu.ac.jp 
tables and allometric equations are developed based on extensive measurements of cut down trees through in-situ destructive sampling (Ash and Helman 1990).

Based on the aforementioned, a nondestructive, practical and efficient in-situ sampling approach is desperately needed to address the problem of large data volume, and enhance data quality, as well as improve our understanding of stem volume estimation in this region. One of the nondestructive tools which have recently received a lot of attention is the terrestrial laser scanning (TLS). TLS has proved to be an effective means of producing highly detailed 3D tree information (Vonderach et al. 2012; Eysn et al. 2013; Krooks et al. 2014; Liang et al. 2014). Nölke et al. (2015) applied TLS and successfully estimated stem volume of 12 tropical tree species that have irregular stems. However, a TLS sensor is quite expensive and data processing is labour intensive, often requiring advanced technical skills, which have been a major obstacle for the wide use of this nondestructive approach (Heritage and Large 2009; Zhou et al. 2015).

On the other hand, photogrammetry is a technique for obtaining reliable information on objects by means of measurement and processing of images acquired using film or digital camera (Slama et al. 1980). Dean (2003) applied a terrestrial close-range photogrammetry combined with image processing software and a conventional volume calculation method, to successfully estimate stem and branch volumes of E. regnans trees. As a result of the relatively low cost nature of the terrestrial close-range photogrammetry, and the fact that data acquisition is a relatively simple process, and also, because recent developments in computer technology and processing software allow us to reproduce detailed 3D images, a handful of researchers are now attracted to the application of these techniques to accurately estimate structural characteristics of trees such as: above ground biomass, dbh, and basal area (Surový et al. 2016; Bauwens et al. 2017). However, previously published approaches (Surový et al. 2016; Bauwens et al. 2017) allowed only the reconstruction of a single 3D tree model per process. This compelled us to take multiple photos (e.g. 20 photos) with high overlap from a close-range (e.g. 1- $3 \mathrm{~m}$ distances), for the individual target tree. In order to obtain 3D photo models of all trees within a plot, this process must be repeated, so that the number of times corresponds to the number of trees within the plot. Therefore, it is a time consuming and labour intensive process to collect all the necessary information, to estimate a tree volume within a plot. Since it is only recent that researchers have begun applying terrestrial close-range photogrammetry to measure trees in the field (Forsman et al. 2016; Mikita et al. 2016; Panagiotidis et al. 2016; Mokroš et al. 2018a), an efficient use of the application of this technology is yet to be fully explored.

The goal of this study is to improve the practicality and efficiency of plot level volume estimation using terrestrial close-range photogrammetry. Ability to do this will contribute to the literature or advance our understanding of the science on estimating stem volume of tree species in subtropical regions such as Okinawa. In order to achieve our goal, we carried out the following steps. First, we built samples of reference 3D models for different tree species, by direct measurement, using a motion tracking system. This was then followed by the reconstruction of 3D tree models for those samples using a terrestrial close-range single tree photogrammetry, and a photogrammetric processing software (Agisoft PhotoScan(C). We then compared the volume computed by photogrammetric processing software with the volume computed from the reference $3 \mathrm{D}$ model, in order to evaluate the accuracy of the terrestrial close-range single tree photogrammetry. Secondly, we introduced the approach based on Mokroš et al. (2018b) who tested various combinations of camera orientations, shooting modes and paths for plot level data collection. The proposed approach simultaneously reconstructs 3D images of multiple tree stems within a plot by taking a series of photos along with the route designed to efficiently obtain overlapping photos of all trees within a plot. Finally, we compare the volume computed based on using a terrestrial close-range single tree photogrammetry with the volume computed based on the newly proposed multiple tree photogrammetry, to evaluate the accuracy of this newly proposed approach.

\section{Materials and methods}

\subsection{Building reference $3 \mathrm{D}$ model}

In order to evaluate the accuracy of tree volume estimation of a single tree terrestrial closedrange photogrammetry, we first built reference 3D models based on direct measurements of stem structure using a magnetic motion tracker, Polhemus FASTRAK@(Figure 1). Alternating current (AC) electromagnetic technology of Polhemus, FASTRAK®provides both position and orientation 
data, by tracing a tree surface with the receiver called "stylus", which is a pen shaped device (Figure 2). The device emits a magnetic field with a radius of $2.5 \mathrm{~m}$ with a TX4 source and it's CPU. This record the position of a sensor located within the field. The magnetic field is capable of penetrating wood, which makes it possible to record the complete horizontal perimeter of a stem (Yoshimoto et al. 2014).

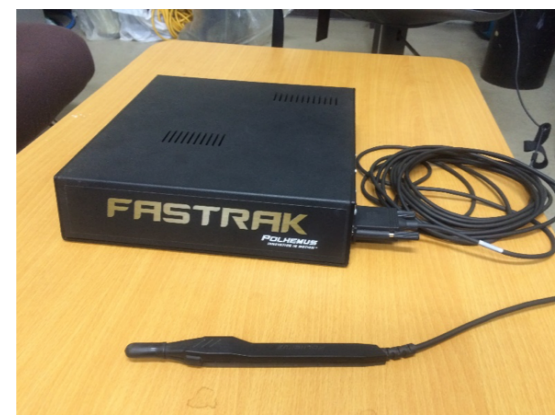

Figure 1. Magnetic motion tracker, Polhemus FASTRAK@.

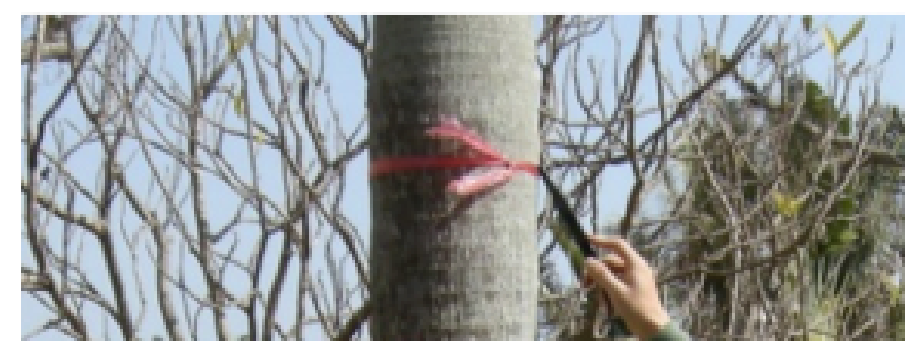

Figure 2. Acquiring position and orientation data by tracing a tree surface with the receiver called "stylus".

Data collections were conducted in the months of November and December in the year 2015. For reference data, we measured four different tree species located on the Senbaru campus of the University of the Ryukyus, in Okinawa (Figure 3). Since the operation of this device required electric supply, the device was plugged into a regular AC power outlet (100-240V) from one of the buildings at the Faculty of Agriculture using a $49 \mathrm{~m}$ extension cord. Sample trees were carefully selected to ensure that they were within $49 \mathrm{~m}$ from the power outlet. Before setting up the system, we identified the tree species and measured the corresponding DBH (diameter at breast height) for each of the trees using a DBH tape. We then mounted a TX4 source on a wooden tripod (Figure 4). The system was set up close to the host computer (Panasonic Toughbook ${ }^{\mathrm{TM}} \mathrm{CF}-30 \mathrm{KW} 1 \mathrm{AA}$ ), to ensure that the system is further away from large metal objects. We identified the receiver and inserted it into the receiver receptacle in order to record three dimensional position ( $\mathrm{x}, \mathrm{y}, \mathrm{z}$ coordinates) of the tree surface. We then recorded the horizontal contours around the stem at every $10 \mathrm{~cm}$ of depth or each significant change in the stem's thickness to a height of approximately $2 \mathrm{~m}$. We used a point visualization and processing software, FastrakDigitizer v1.0, to process point data from FASTRAK@and reconstruct tree surface from point data (Figure 5). The detailed point processing and 3D shape reconstruction, using the software, FastrakDigitizer v1.0, can be found in Yoshimoto et al. (2014).

\subsection{Photo reconstruction of individual stem using a terrestrial close-range single-tree photogrammetry}

Before taking photographs, we placed the reference tape on a stem for later scaling of the three dimensional point cloud produced using the software (Figure 6). Photographs can be taken by any standard digital camera with reasonably high resolution (5 MPix or more), as long as some specific capturing guidelines are followed, such as "shoot pictures of the scene with lots of overlaps" and "more photos is better than not enough" (Agisoft PhotoScan(C) User Manual 2012). In this study, we 


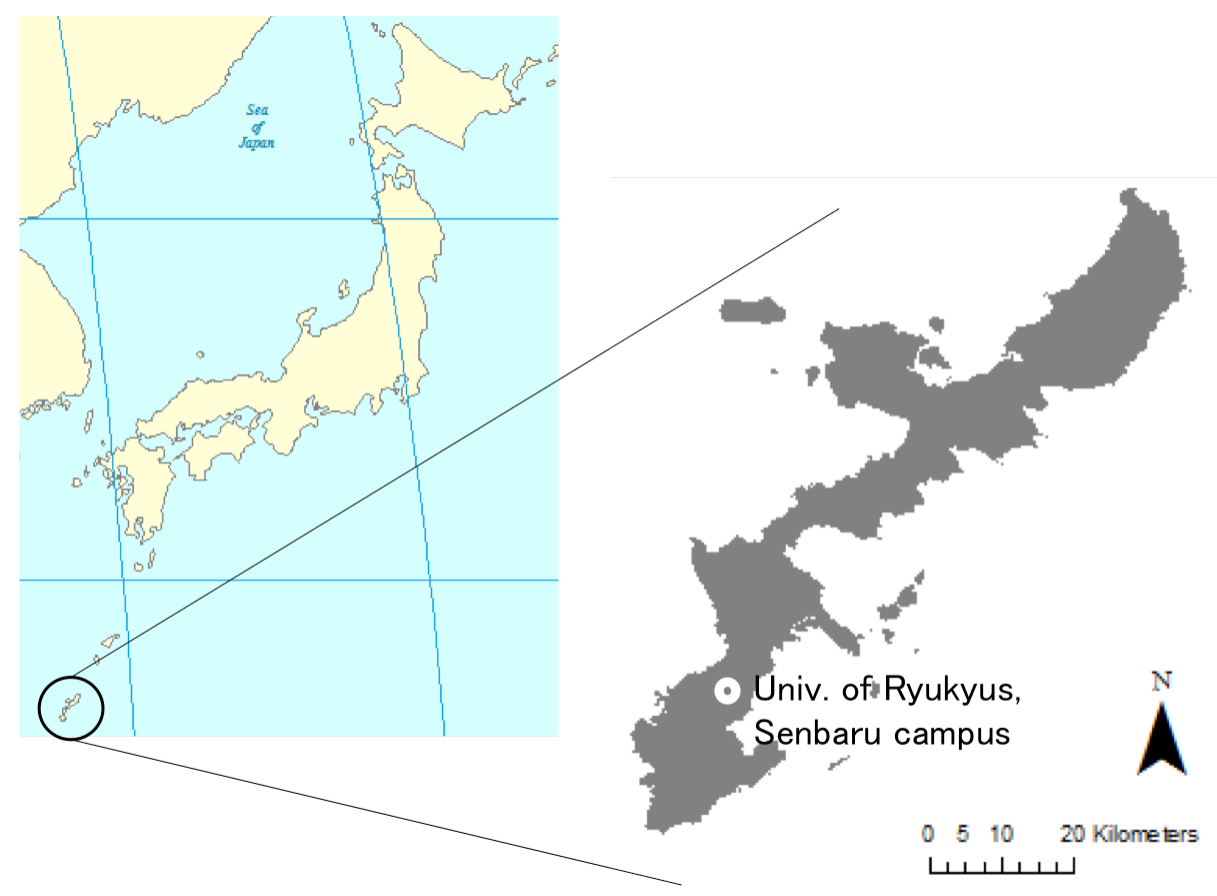

Figure 3. Location of the research area in Okinawa prefecture, Japan.

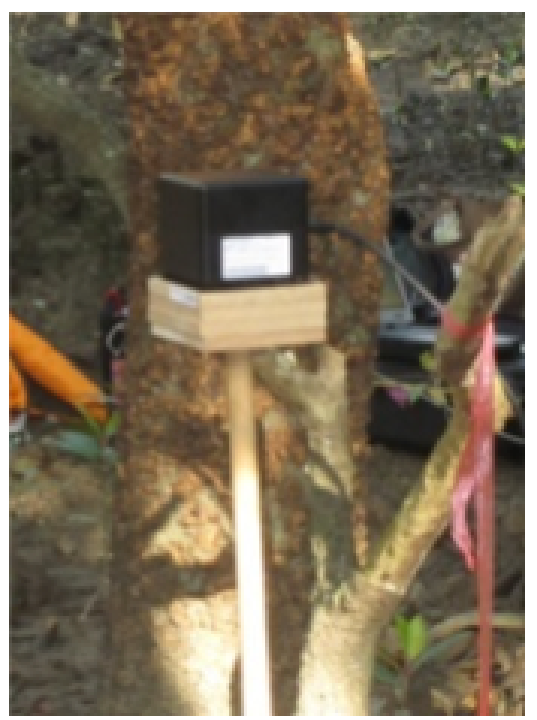

Figure 4. Mounting TX4 source on a wooden tripod. 


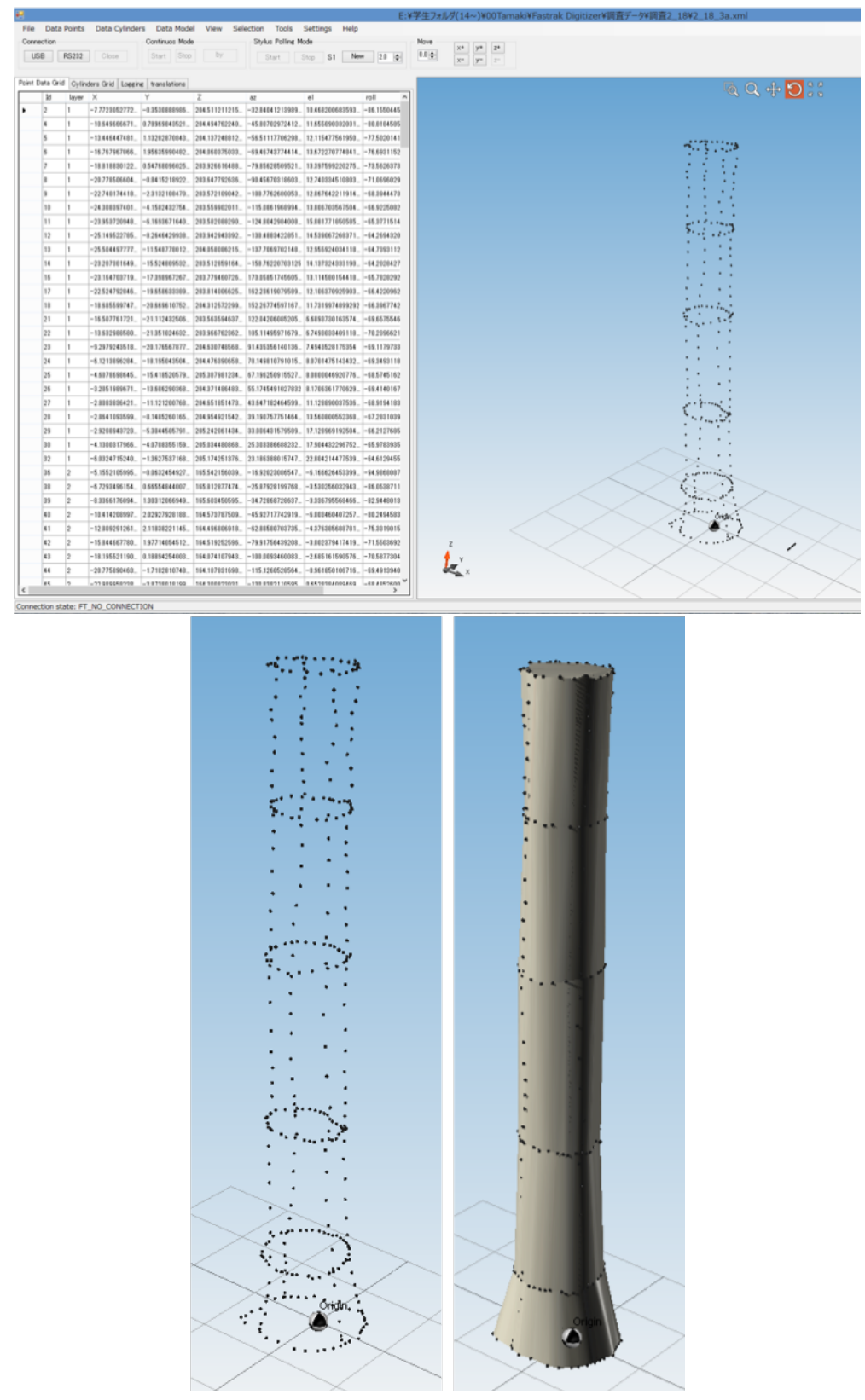

Figure 5. Processing point data using FASTRAK@and reconstruct tree surface from point data using FastrakDigitizer v1.0. 
took photos using Nikon D7000 with an 18-105 mm f/3.5-5.6 VR lens. The distance from the camera to the tree was set between 1-2 m. As described in Surový et al. (2016) and Bauwens et al. (2017), we took a set of photographs around the tree so that it covered every angle possible with high degree of overlap (60\% of each image overlapped with another image) (Figure 7 ). We took approximately 30-60 photos per tree. We then loaded the photos into a photo-grammetric processing software (Agisoft PhotoScan(C), which was installed using an HP EliteDesk 800 G1 TWR with 16GB RAM, and an Intel R CoreTM i7- 4790 @ 3.6Ghz, as well as an Intel HD Graphics 4600 graphic card. The next step was to align the photos and reconstruct the sparse and dense point cloud using Agisoft PhotoScan(C). The professional edition of Agisoft PhotoScan(C) has an inbuilt tool to measure a tree volume and surface area using reconstructed 3D images.

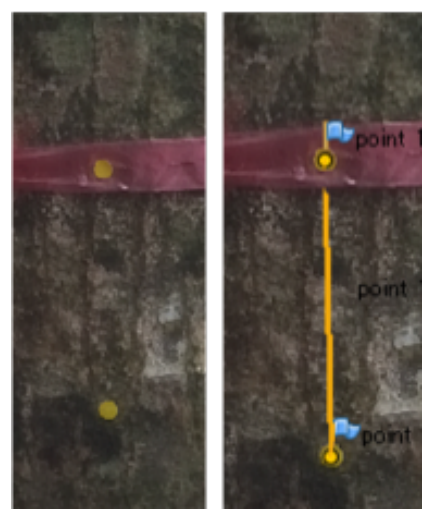

Figure 6. Placing the reference tape on a stem.

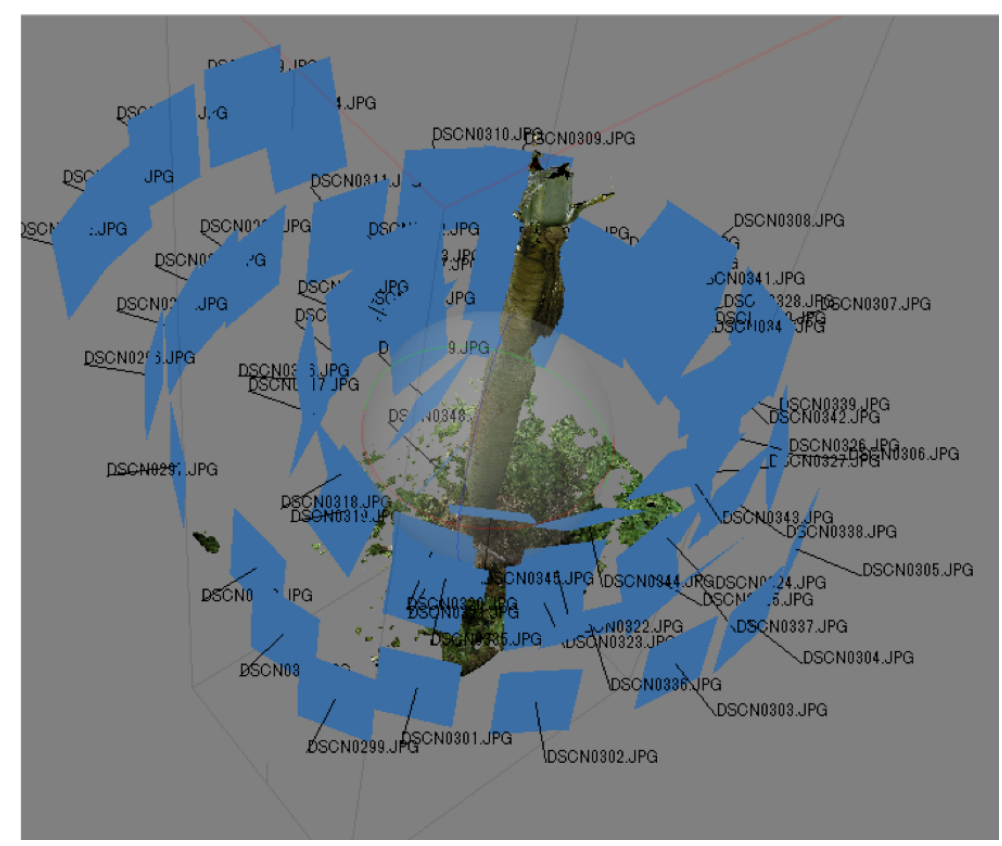

Figure 7. Taking a set of photographs around the tree with high degree of overlap. 


\subsection{Photo reconstruction of multiple stems within a plot using a terrestrial close-range multiple-tree photogrammetry}

We established a sample plot of $10 \mathrm{~m} \times 10 \mathrm{~m}$ (0.01 ha), within a small green area across the parking lot of the Faculty of Agriculture. This area was planted with Bischofia javanica tree species. Before taking the photographs, tree species were identified and corresponding DBH (diameter at breast height) was measured for each of the trees using a DBH tape. We also assigned specimen identification number to each tree and placed the reference tape on the stem. This was later used to scale the three dimensional point cloud produced through the software. We then took a set of photographs for each individual tree, starting with the specimen identification number of one, as described in the section 1.2. This process continued until a set of photographs was taken for the last specimen within the plot. This was followed by loading each set of photos separately into a photogrammetric processing software, to reconstruct a 3D photo model for each specimen. The volume computed was reported for each specimen.

In order to explore a more efficient data collection process, unlike the photogrammetric measurement of an individual stem, we took a series of photos capturing the plot condition while walking through the plot. The walking route was designed to efficiently obtain overlapping photos of all trees within the plot (Figure 8). The process works by selecting one corner of the plot as a starting point. This is followed by walking slowly and taking photos between trees planted in lines. As shown in Figure 8, after capturing all possible angles of the most outer side of planted lines, the next logical step is to move to the next planted line and walk slowly proceed to the side of the starting point, parallel to the initial line. After this, the next step is to move to the planted line that follows. This process continues until the other edge of the plot is reached. Through this process, all perpendicular lines between planted lines were captured, only after all horizontal lines were captured. Finally, all photos were loaded into a photogrammetric processing software to reconstruct the $3 \mathrm{D}$ photo models for all specimen within a plot. The software can report the volume for each tree computed using simultaneously reconstructed multiple 3D tree models.

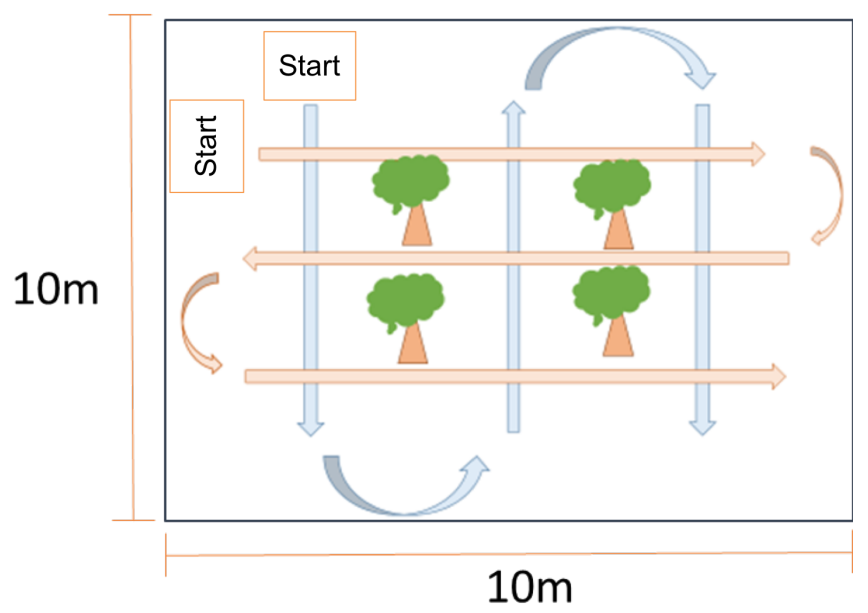

Figure 8 . The walking route designed to efficiently obtain overlapping photos.

\subsection{Evaluating the accuracy of the proposed terrestrial close-range photogrammetry}

Surface point data obtained from direct measurement of trees in the field using magnetic motion tracker, Polhemus FASTRAK@were processed using point processing software, FastrakDigitizer v1.0. This software reconstructs 3D stem shape from the point clouds obtained from the surface measurement using computer-aided design technique which calculates the cross sectional area, surface area and volume (Yoshimoto et al. 2014). FASTRAK®and the software have been utilized in the precise measurement of stem volume (Yoshimoto et al. 2014) and have also been utilized in the direct measurement of tree stem structures (Surový et al. 2016). For 3D photo modelling based on terrestrial close-range photogrammetry, we used the professional edition of Agisoft PhotoScan (c) to 
compute tree stem volume.

The root mean square error (RMSE) between the volumes computed based on filed measurements using a magnetic motion tracker and those computed from reconstructed 3D photos was calculated using the following equation.

$$
R M S E=\sqrt{\frac{\sum_{i=1}^{n}\left(V o l_{p}-V o l_{d}\right)^{2}}{n}}
$$

where $V o l_{p}$ represents the volume computed from reconstructed 3D photo model; $V o l_{d}$, the volume computed from direct field measurement; and $n$, the total number of samples.

For evaluating the accuracy of multiple-trees photogrammetry, the RMSE between the volumes computed based on a single-tree photogrammetry (whose accuracy has been tested in Eq.[1]) and those computed based on multiple-tree photogrammetry was calculated using the following equation.

$$
R M S E=\sqrt{\frac{\sum_{i=1}^{n}\left(V o l_{m}-V o l_{s}\right)^{2}}{n}}
$$

where $V o l_{m}$, represents the volume computed based on multiple-tree photogrammetry; $V o l_{s}$, the volume computed based on a single-tree photogrammetry; and $n$, the total number of samples within the plot.

\section{Results}

\subsection{Accuracy of stem volume using a single-tree photogrammetry}

Four reference trees selected include three known species: Bischofia javanica; Terminalia catappa L.; and Mascarena verschaffeltii L.H.Bailey; and one unknown species of Arecaceae. Table 1 summarizes the basic attributes of the reference trees. Figure 9(b), 10(b), 11(b), and 12(b) show reconstructed 3D trees using a magnetic motion tracker, and a point processing and visualization software, FastrakDigitizer v1.0. As shown in Figure 9(b), 10(b), 11(b), and 12(b), surface texture was successfully recovered from point clouds, using a magnetic motion tracker. Figure 9(c), 10(c), 11(c), and 12(c) show 3D photo models developed using a single-tree terrestrial close-range photogrammetry. The volume estimation from a direct measurement and the volume estimation from a single-tree terrestrial close-range photogrammetry for the four sample trees are shown in Table 2. The table also shows the surface area estimation from the two approaches. Table 3 summarizes the results of the RMSE. The error of the volume calculated using a magnetic motion tracker and FastrakDigitizer v1.0 is $0.0053 \mathrm{~m}^{3}$. This is different from the one estimated from a single-tree terrestrial close-range photogrammetry. Its variability is 0.0327 . The error of surface area calculated using a magnetic motion tracker and FastrakDigitizer v1.0 is $0.0714 \mathrm{~m}^{2}$, different from the one estimated from a single-tree terrestrial close-range photogrammetry. Its variability is 0.2734 .

Table 1. Summary of reference trees' attributes.

\begin{tabular}{llrr}
\hline ID & Species & DBH $(\mathrm{cm})$ & Height $(\mathrm{m})$ \\
\hline 1 & Bischofia javanica & 24.0 & 2.01 \\
2 & Terminalia catappa L. & 30.9 & 2.04 \\
3 & Mascarena verchaffeltii L.H.Bailey & 22.4 & 2.00 \\
\multirow{2}{*}{4} & Unknown species of & 22.3 & 2.09 \\
& Arecaceae & & \\
\hline
\end{tabular}




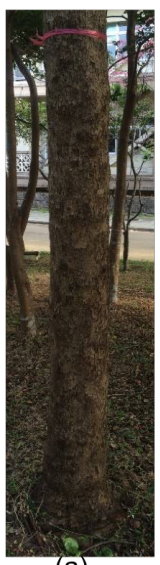

(a)

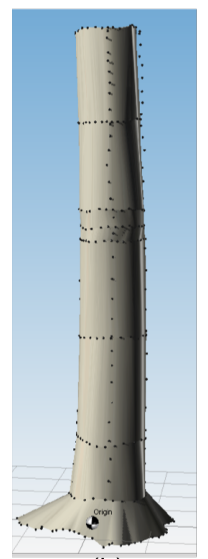

(b)

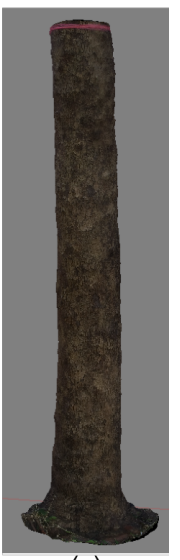

(c)

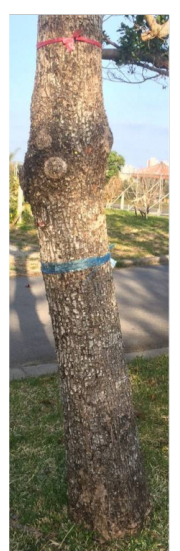

(a)

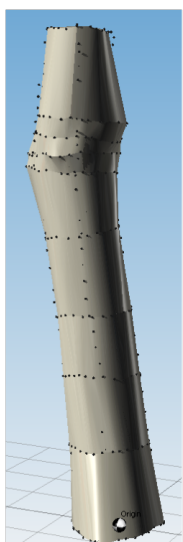

(b)

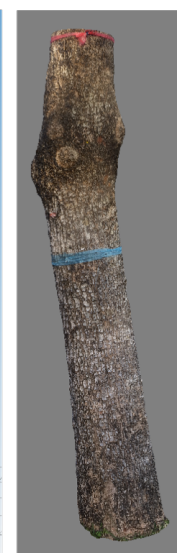

(c)
Figure 9. Comparison of reconstructed 3D models of Bischofia javanica.

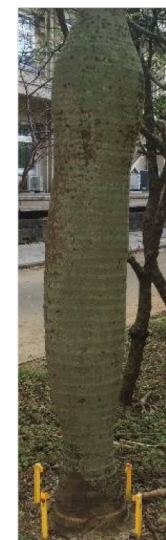

(a)

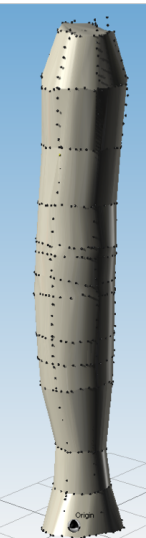

(b)

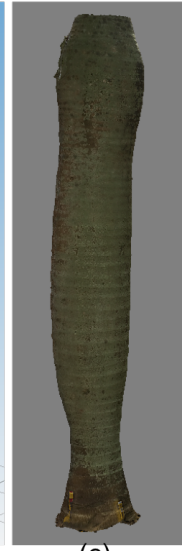

(c)
Figure 11. Comparison of reconstructed 3D models of Mascarena verschaffeltii L.H.Bailey.
Figure 10. Comparison of reconstructed 3D models of Terminalia catappa L.

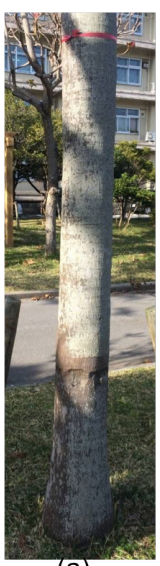

(a)

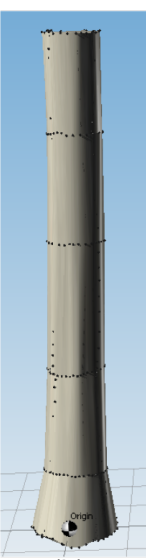

(b)

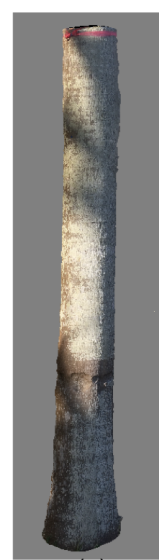

(c)
Figure 12. Comparison of reconstructed 3D models of unknown species of Arecaceae.

\subsection{Accuracy of stem volumes using multiple-tree photogrammetry}

Figure 13 shows the results of all the 11 reconstructed 3D tree models within the plot. The mean $\mathrm{DBH}$ of the plot is $15.9 \mathrm{~cm}$ (the maximum DBH and the minimum DBH are $24.9 \mathrm{~cm}$ and $7.8 \mathrm{~cm}$ respectively). Three specimens (ID5, ID9, ID10) are forked around the breast height. Therefore, each stem was measured separately for those tree specimens (Table 4). It took about 90 minutes and 420 photos to cover all trees within a plot. Based on the aforementioned results, we compared the volume computed based on a 3D photo model developed by a single-tree terrestrial close-range photogrammetry with the volume computed based on 3D photo models developed by multiple-tree terrestrial close-range photogrammetry. For each specimen we plotted the volume computed based on a single-tree photogrammetry against the volume computed based on multiple-tree photogrammetry, in order to evaluate the accuracy of multiple-tree terrestrial close-range photogrammetry. This crossplot is shown in Figure 14. If two values are identical to each other, the pairs fall on the 45 degree line. As shown in Figure14, all paired data fall close to the 45 degree line. The differences in volume computation seem large in ID2, ID3 and ID9 compared with others specimens. These three specimens have the largest DBH within the plot (Table 4). Table 5 summarizes the results of the RMSE. The differences in volume and surface area have a corresponding error of $0.0128 \mathrm{~m}^{3}$ and $0.1940 \mathrm{~m}^{2}$, respectively. Their variabilities are 0.0510 and 0.7736 , respectively. 
Table 2. Volume and surface area computed based on direct measurement and photogrammetry.

\begin{tabular}{|c|c|c|c|c|}
\hline ID & Species & & Direct measurement & Photogrammetry \\
\hline \multirow{2}{*}{1} & \multirow{2}{*}{ Bischofia javanica } & Volume $\left(m^{3}\right)$ & 0.1110 & 0.1007 \\
\hline & & Surface $\left(m^{2}\right)$ & 2.0183 & 1.8821 \\
\hline \multirow{2}{*}{2} & \multirow{2}{*}{ Terminalia catappa L. } & Volume $\left(m^{3}\right)$ & 0.1587 & 0.1562 \\
\hline & & Surface $\left(m^{2}\right)$ & 2.2518 & 2.2121 \\
\hline \multirow{2}{*}{3} & Mascarena verchaffeltii & Volume $\left(m^{3}\right)$ & 0.1451 & 0.1457 \\
\hline & L.H.Bailey & Surface $\left(m^{2}\right)$ & 2.0910 & 2.1071 \\
\hline \multirow{2}{*}{4} & Unknown species of & Volume $\left(m^{3}\right)$ & 0.0865 & 0.0858 \\
\hline & Arecaceae & Surface $\left(m^{2}\right)$ & 1.6095 & 1.6050 \\
\hline
\end{tabular}

Table 3. The root mean square error (RMSE) and standard deviation (SD) of volume and surface area calculated from photo reconstruction models and direct measurement.

\begin{tabular}{lrr}
\hline & RMSE & SD \\
\hline Volume $\left(m^{3}\right)$ & 0.053 & 0.0327 \\
Surface Area $\left(m^{2}\right)$ & 0.0714 & 0.2734 \\
\hline
\end{tabular}

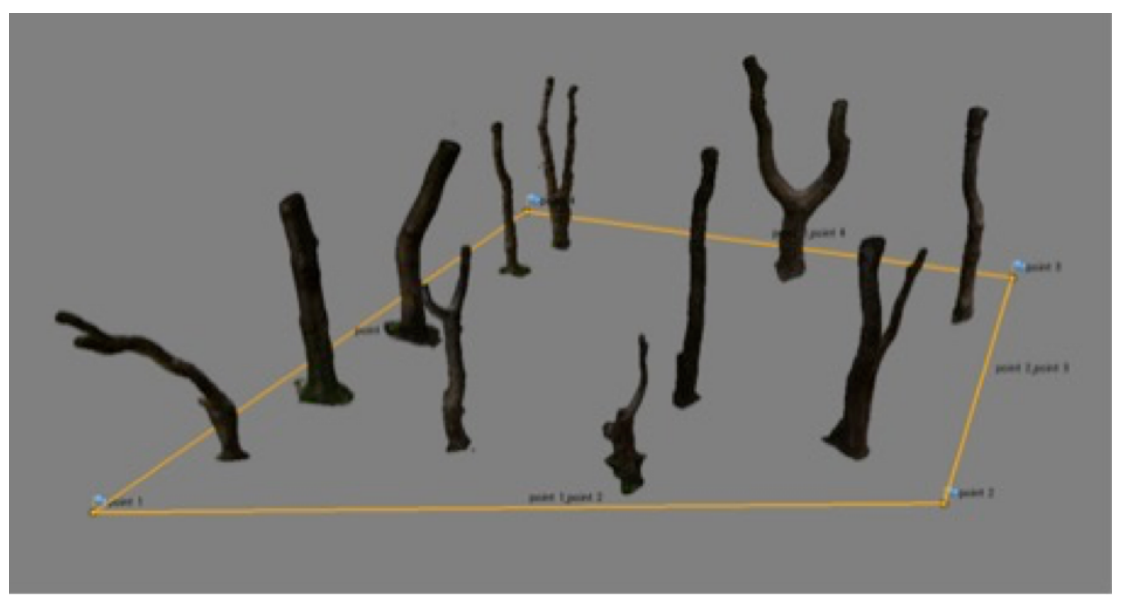

Figure 13. Reconstruction of multiple 3D stems by photogrammetry and Agisoft PhotoScan@ within the plot.

Table 4. Diameter at breast height $(\mathrm{dbh}, \mathrm{cm})$ for trees in the plot.

\begin{tabular}{lll}
\hline ID & DBH $(\mathrm{cm})$ & Remarks \\
\hline 1 & 14.2 & \\
2 & 24.9 & \\
3 & 24.8 & \\
4 & 12.3 & \\
5 & $9.8,9.5$ & forked \\
6 & 15.5 & \\
7 & 7.8 & \\
8 & 15.5 & \\
9 & $20.5,18.6$ & forked \\
10 & $19.1,10.5$ & forked \\
11 & 15.6 & \\
\hline
\end{tabular}




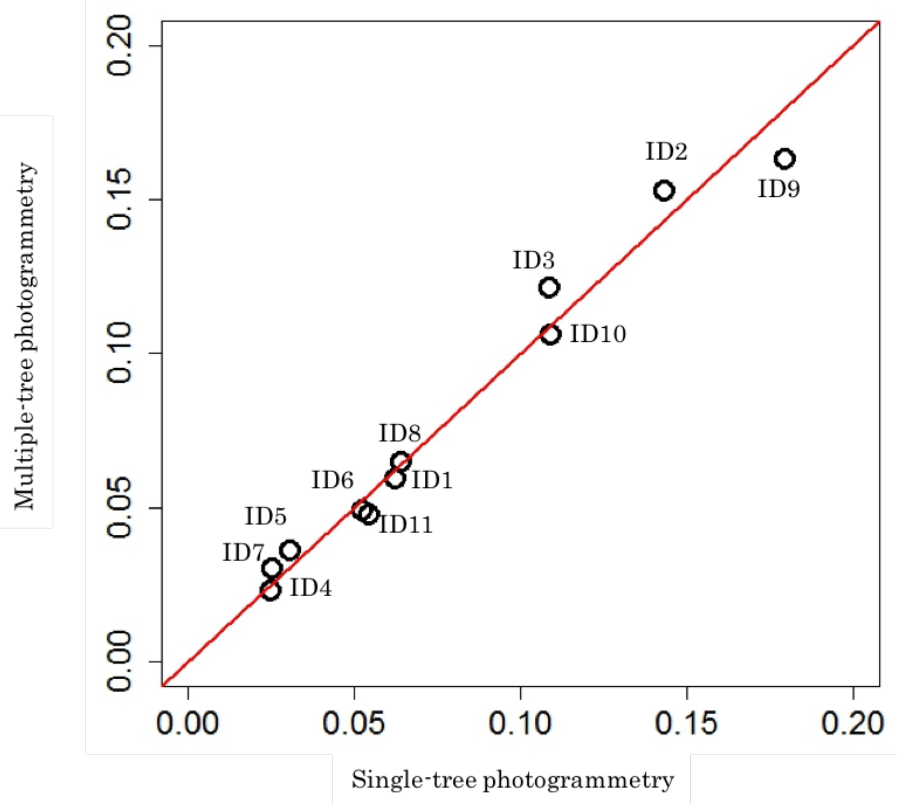

Figure 14. Comparison of the volume estimated from multiple-tree photogrammetry with volume estimated from single-tree photogrammetry.

Table 5. The root mean square error (RMSE) and standard deviation (SD) of volume and surface area calculated from single-tree photogrammetry and multiple-tree photogrammetry.

\begin{tabular}{lrr}
\hline & RMSE & SD \\
\hline Volume $\left(m^{3}\right)$ & 0.0128 & 0.0510 \\
Surface Area $\left(m^{2}\right)$ & 0.1940 & 0.7736 \\
\hline
\end{tabular}

\section{Discussion}

In this study, we turned our attention to a relatively old sampling technique, terrestrial closerange photogrammetry, as a nondestructive, practical and efficient in-situ sampling approach. We chose this approach because it is less costly compared to the current high profile technique, the terrestrial laser scanning (TLS). Despite the recent advances in computer technology that allows us to reproduce detailed 3D images, terrestrial close-range photogrammetry has not been well studied nor fully explored. There is a need to investigate its usefulness compared with the aforementioned TLS. It must be pointed out that we don't have an established system in place even for the very basic data collection protocol for terrestrial close-range photogrammetry, which can be easily and widely be applied to subtropical forest.

Our results reveal that with a high level of precision, this approach can be used to estimate the volume of a single stem. Our results also show that this approach can easily be extended to successfully reconstruct $3 \mathrm{D}$ photo models of multiple trees within a plot. We also showed that the volume computed for each single stem based on multi-tree terrestrial close-range photogrammetry, is comparable to the volume computed based on a single tree terrestrial close-range photogrammetry. Although, the differences in volume computation seem larger for the larger DBH trees, the proposed approach was fairly able to estimate the volume of tree with complicated structures, such as a tree forked at breast height. In addition to stem volume computation, this tool can be used to develop a tree position map within the plot. As shown in Figure 13, a 3D model generated from a series of photos taken along the carefully designed route is actually a $3 \mathrm{D}$ tree map representing relative locations of stems with each other.

In this study, the measurement was limited to the main stem below the crown (i.e. the bole). 
This is because, it remains a challenging task to accurately measure upper stems and crowns of individual tree without using destructive methods (Henning and Radtke 2006). Dean (2003) used a geographic information system (GIS) to digitize the images of branches, divided them into thin (0.001 m deep) cross-sections, each of which approximates a conic section, and tallied the volume of each thin section for estimating the total volume of branches. According to Dean (2003) the proportion of branch volume to the total stem volume differs, depends on species. For example, S.giganteum's total branch volume corresponds to less than $5 \%$ of the total volume of the tree, while Q. rabur's total branch volume corresponds to almost 30\% of the total stem volume (Dean 2003). Future studies might consider using Dean's (2003) labor-intensive method to further improve our estimate of tree volumes, if there is a high proportion of branch volume that cannot be ignored.

Also the reconstruction of $3 \mathrm{D}$ stem models in our study was constrained by available data acquisition equipment. For example, if our motion tracking system was used in conjunction with portable equipment such as portable generator, the selections of our reference models would not be limited by the length of the extension cord and/or the location of power outlet available.

\section{Conclusions}

Estimating stem volume of a tree is an essential part of evaluating the amount of carbon storage in trees since the amount of carbon storage in trees is dependent on tree size. For most commercial tree species in Japan, various equations and volume tables have been used to estimate stem volume using tree attributes such as "height" and "DBH", which are measured in the field. However, there is a lack of data and information for estimating stem volume in subtropical forest (Takashima 2011; Wu et al. 2015; Xu et al. 2015; Xiang et al. 2016). Although extensive in-situ destructive sampling are often required at an earlier stage of data collection for estimating biomass or tree volume (Ash and Helman 1990), public interest and awareness for cutting trees in Okinawa has been unwavering and ever growing, especially after the Japanese Ministry of the Environment (MOE) submitted to UNESCO its intensions to nominate northern parts of Okinawa Island along with other neighboring Islands as a World Heritage site. In this study, to collect data on stem volume effectively and efficiently without disturbing the surroundings, we evaluated the usefulness and limitations of the terrestrial close-range photogrammetry in subtropical forest. Despite several key advantages such as low cost and user-friendliness of photogrammetry, only a few studies have applied terrestrial close-range photogrammetry for tree measurement in the field compared with TLS. This is the first known study in peer review literature to attempt to capture, and reconstruct structures of multiple trees simultaneously, with terrestrial close-range photogrammetry in subtropical forest.

Although limitations listed in the previous section must be acknowledged and must be addressed in order to successfully apply the proposed new approach, as a nondestructive, practical and efficient in-situ sampling approach, this study showed that photogrammetry combined with the latest image processing software could provide a simple way to estimate stem volume and collect those data in subtropical forest where human activities (such as cutting trees) are often restricted. The proposed approach may be used in place of TLS especially in sub-tropical and tropical forests, located in developing countries where affordability of TLS will be difficult both technically and financially.

\section{Acknowledgement}

This research was partially supported by a Grant-in-Aid for Scientific Researches (No. 16K12641\& 17H00806) from the Ministry of Education, Culture, Sports, Science, and technology of Japan. The authors are grateful to Atsushi Yoshimoto and Peter Surový for comments and advice.

\section{References}

Ash, J., Helman, C. (1990) Floristics and vegetation biomass of a forest catchment, Kioloa, south coastal New South Wales, Cunninghamia. 2: 167-182.

Arief, W. (2009) Evaluation of ALOS palsar mosaic data for estimating stem volume and biomass: a case study from tropical rainforest of central Indonesia, Jurnal Geografi. 2: 14-21.

Bauwens, S., Fayolle, A., Gourlet - Fleury, S., Ndjele, L.M., Mengal, C., Lejeune, P. (2017) Terres- 
trial photogrammetry: a nondestructive method for modelling irregularly shaped tropical tree trunks, Methods Ecol. Evol. 8(4): 460-471.

Dean, C. (2003). Calculation of wood volume and stem taper using terrestrial single-image closerange photogrammetry and contemporary software tools, Silva Fenn. 37(3): 359-380.

Drake, J.B., Dubayah, R.O., Clark, D.B., Knox, R.G., Blair, J.B., Hofton, M.A., ..., Prince, S. (2002) Estimation of tropical forest structural characteristics using large-footprint lidar, Remote Sens. Environ. 79(2-3): 305-319.

Eggleston, S., Buendia, L., Miwa, K., Ngara, T., Tanabe, K. (eds.) (2006) 2006 IPCC guidelines for national greenhouse gas inventories, Hayama, Japan: Institute for Global Environmental Strategies.

Eysn L., Pfeifer N., Ressl C., Hollaus M., Grafl A., Morsdorf F. (2013) Practical approach for extracting tree models in forest environments based on equirectangular projections of terrestrial laser scans, Remote Sensing. 5: 5424-5448.

Forsman, M., Börlin, N., Holmgren, J. (2016) Estimation of tree stem attributes using terrestrial photogrammetry with a camera rig, Forests. 7(3): 61.

Henning, J.G., Radtke, P.J. (2006) Detailed stem measurements of standing trees from ground-based scanning lidar, Forest Sci. 52(1): 67-80.

Heritage, G.L., Large, A.R.G. (eds.) (2009) Laser Scanning for the Environmental Sciences, London, WileyBlackwell, 278 p.

Intergovernmental Panel on Climate Change (IPCC) (2014) Climate Change 2014: Mitigation of Climate Change: Working Group III Contribution to the Fifth Assessment Report of the Intergovernmental Panel on Climate Change, Cambridge University Press.

Krooks, A., Kaasalainen, S., Kankare, V., Joensuu, M., Raumonen, P., Kaasalainen, M. (2014) Predicting tree structure from tree height using terrestrial laser scanning and quantitative structure models, Silva Fenn. 48: 1125.

Liang, X., Kankare, V., Yu, X., Hyyppä, J., Holopainen, M. (2014) Automated stem curve measurement using terrestrial laser scanning, IEEE T. Geosci. Remote. 52: 1739-1748.

Mikita, T., Janata, P., Surový, P. (2016) Forest stand inventory based on combined aerial and terrestrial close-range photogrammetry, Forests. 7(8): 165.

Mokroš, M., Výboštok, J., Tomaštík, J., Grznárová, A., Valent, P., Slavík, M., Merganič, J. (2018a) High precision individual tree diameter and perimeter estimation from close-range photogrammetry, Forests. 9(11): 696.

Mokroš, M., Liang, X., Surový, P., Valent, P., Čerňava, J., Chudý, F., ..., Merganič, J. (2018b) Evaluation of close-range photogrammetry image collection methods for estimating tree diameters, ISPRS Int. J. Geo-Inf. 7(3): 93.

Nöke, N., Fehrmann, L., I Nengah, S.J., Tiryana, T., Seidel, D., Kleinn, C. (2015) On the geometry and allometry of big-buttressed trees - a challenge for forest monitoring: New insights from 3D-modeling with terrestrial laser scanning, iForest. 8(5): 574-581.

Okinawa Prefecture (2017) Introduction of carbon certificate program in Okinawa (in Japanese: Title is translated by the author) <http://www.pref.okinawa.jp/site/kankyo/saisei/ ryokuka/co2.html $>$ (Accessed 7 June 2018).

Okinawa Godo Law Office (2018) The statement of protest against cutting trees in Kunigami-son, Okinawa (in Japanese: Title is translated by the author) $<$ http://okinawagodo.org /blog/1018/> (Accessed 7 June 2018).

Omar, H., Ismail, M.H., Hamzah, K.A., Shafri, H.Z.M., Kamarudin, N. (2014) Forest biomass assessments with special reference to L-Band Alos Palsar data, The Malaysian Forester. 77(1):118. 
Panagiotidis, D., Surový, P., Kuželka, K. (2016) Accuracy of structure from motion models in comparison with terrestrial laser scanner for the analysis of DBH and height influence on error behaviour, J. Forest Sci. 62(8): 357-365.

Slama, C., Theurer, C., Henriksen, S. (eds.) (1980) Manual of Photogrammetry, 4th edition, American Society for Photogrammetry and Remote Sensing

Surový, P., Yoshimoto, A., Panagiotidis, D. (2016) Accuracy of reconstruction of the tree stem surface using terrestrial close-range photogrammetry, Remote Sensing. 8(2):123.

Takashima, A. (2011) Examining the stand growth of natural subtropical forest in Yambaru region of Okinawa (in Japanese, with title translated by the authors), Proc. Ann. Jpn. Forest Soc. 554 .

Vonderach C., Voegtle T., Adler P. (2012) Voxel-based approach for estimating urban tree volume from terrestrial laser scanning data, Int. Arch. Photogramm. Remote Sens. Spat. Info. Sci. 39: $451-456$.

Wu, X., Wang, X., Wu, Y., Xia, X., Fang, J. (2015) Forest biomass is strongly shaped by forest height across boreal to tropical forests in China, J. Plant. Ecol. 8(6): 559-567.

Xiang, W., Zhou, J., Ouyang, S., Zhang, S., Lei, P., Li, J., ..., Forrester, D.I. (2016) Species-specific and general allometric equations for estimating tree biomass components of subtropical forests in southern China, Eur. J. For. Res. 135(5): 963-979.

Xu,Y.Z., Zhang, J.X., Franklin, S.B., Liang, J., Ding, P., Luo, Y., ..., Jiang, M. (2015) Improving allometry models to estimate the above and belowground biomass of sub-tropical forest, China, Ecosphere. 6:1-15.

Yoshimoto, A., Surový, P., Konoshima, M., Kurth, W. (2014) Constructing tree stem form from digitized surface measurements by a programming approach within discrete mathematics, Trees. 28(6): $1577-1588$.

Zhou, Z., Gong, J., Guo, M. (2015) Image-based 3D reconstruction for posthurricane residential building damage assessment, J. Comput. Civil. Eng. 30(2): 04015015. 